\title{
Corrigendum: Viewing Meaningful Work Through the Lens of Time
}

\author{
Francesco Tommasi ${ }^{*}$, Andrea Ceschi and Riccardo Sartori \\ Human Sciences Department, University of Verona, Verona, Italy
}

Keywords: meaningful work, meaningfulness, time-based definition, temporal framework, work and organizational psychology

\section{A Corrigendum on}

Viewing Meaningful Work Through the Lens of Time

by Tommasi, F., Ceschi, A., and Sartori, R. (2020). Front. Psychol. 11:585274. doi: $10.3389 /$ fpsyg.2020.585274

In the original article, the reference for ${ }^{* *}$ (Costantini et al., 2017b)** was incorrectly written as ** Costantini, A., Riccardo, S., and Andrea, C. (2017b). "Framing workplace innovation through an organisational psychology perspective: a review of current WPI studies," in Aligning perspectives on health, safety and well-being. Workplace innovation: Theory, research and practice, eds P. R. A. Oeij, D. Rus, and F. D. Pot (Cham: Springer), 131-147. doi: 10.1007/978-3-319-56333-6_9**. It should be ** Costantini, A., Sartori, R., and Ceschi, A. (2017b). "Framing workplace innovation through an organisational psychology perspective: a review of current WPI studies," in Aligning Perspectives on Health, Safety and Well-being. Workplace Innovation: Theory, Research and Practice, eds P. R. A. Oeij, D. Rus, and F. D. Pot (Cham: Springer), 131-147. doi: 10.1007/978-3-319-56333-6_9**.

In the original article, the reference for ${ }^{* *}$ (Costantini et al., 2019)** was incorrectly written as ** Costantini, A., Andrea, C., and Riccardo, S. (2019). “The theory of planned behaviour as a frame for job crafting: explaining and enhancing proactive adjustment at work," in Theoretical Approaches to Multi-Cultural Positive Psychological Interventions, eds L. Van Zyl, and S. Rothmann, Sr. (Cham: Springer), 161-177. doi: 10.1007/978-3-030-20583-6_7**. It should be **Costantini, A., Ceschi, A., and Sartori, R. (2019). "The theory of planned behaviour as a frame for job crafting: explaining and enhancing proactive adjustment at work," in Theoretical Approaches to Multi-Cultural Positive Psychological Interventions, eds L. Van Zyl, and S. Rothmann, Sr. (Cham: Springer), 161-177. doi: 10.1007/978-3-030-20583-6_7**.

The authors apologize for this error and state that this does not change the scientific conclusions of the article in any way. The original article has been updated.

\section{REFERENCES}

This article was submitted to Organizational Psychology, a section of the journal Frontiers in Psychology

Received: 13 October 2020 Accepted: 20 October 2020 Published: 16 November 2020

Citation:

Tommasi F, Ceschi A and Sartori $R$ (2020) Corrigendum: Viewing Meaningful Work Through the Lens of Time. Front. Psychol. 11:616916. doi: 10.3389/fpsyg.2020.616916

Costantini, A., Ceschi, A., and Sartori, R. (2019). “The theory of planned behaviour as a frame for job crafting: explaining and enhancing proactive adjustment at work," in Theoretical Approaches to Multi-Cultural Positive Psychological Interventions, eds L. Van Zyl, and S. Rothmann, Sr. (Cham: Springer), 161-177. doi: 10.1007/978-3-030-20583-6_7

Costantini, A., Sartori, R., and Ceschi, A. (2017b). "Framing workplace innovation through an organisational psychology perspective: a review of current WPI studies," in Aligning Perspectives on Health, Safety and Well-being. Workplace Innovation: Theory, Research and Practice, eds P. R. A. Oeij, D. Rus, and F. D. Pot (Cham: Springer), 131-147. doi: 10.1007/978-3-319-56333-6_9

Copyright (c) 2020 Tommasi, Ceschi and Sartori. This is an open-access article distributed under the terms of the Creative Commons Attribution License (CC BY). The use, distribution or reproduction in other forums is permitted, provided the original author(s) and the copyright owner(s) are credited and that the original publication in this journal is cited, in accordance with accepted academic practice. No use, distribution or reproduction is permitted which does not comply with these terms. 